\title{
Plasma Potential and Langmuir Probe Measurements in the Near-field Plume of the NASA-457Mv2 Hall Thruster
}

\author{
Rohit Shastry ${ }^{*}$, Wensheng Huang ${ }^{\dagger}$, Daniel A. Herman ${ }^{\ddagger}$, George C. Soulas ${ }^{\S}$, and Hani Kamhawi** \\ NASA Glenn Research Center, Cleveland, $\mathrm{OH}, 44135$
}

In order to further the design of future high-power Hall thrusters and provide experimental validation for ongoing modeling efforts, plasma potential and Langmuir probe measurements were performed on the 50-kW NASA-457Mv2. An electrostatic probe array comprised of a near-field Faraday probe, single Langmuir probe, and emissive probe was used to interrogate the near-field plume from approximately $0.1-2.0$ mean thruster diameters downstream of the thruster exit plane at the following operating conditions: 300 $\mathrm{V}, 400 \mathrm{~V}$ and $500 \mathrm{~V}$ at $30 \mathrm{~kW}$ and $500 \mathrm{~V}$ at $50 \mathrm{~kW}$. Results have shown that the acceleration zone is limited to within 0.4 mean thruster diameters of the exit plane while the hightemperature region is limited to $\mathbf{0 . 2 5}$ mean thruster diameters from the exit plane at all four operating conditions. Maximum plasma potentials in the near-field at 300 and $400 \mathrm{~V}$ were approximately $50 \mathrm{~V}$ with respect to cathode potential, while maximum electron temperatures varied from $24-32 \mathrm{eV}$, depending on operating condition. Isothermal lines at all operating conditions were found to strongly resemble the magnetic field topology in the high-temperature regions. This distribution was found to create regions of high temperature and low density near the magnetic poles, indicating strong, thick sheath formation along these surfaces. The data taken from this study are considered valuable for future design as well as modeling validation.

\section{Nomenclature}

$C \quad=$ line capacitance

$D_{T, m} \quad=$ mean thruster diameter

$I_{\text {cap }} \quad=$ capacitive current

$\dot{m}_{a} \quad=$ anode mass flow rate

$P_{d} \quad=$ discharge power

$T \quad=$ thrust

$T_{e} \quad=$ electron temperature

$\eta_{a} \quad=$ anode efficiency

\section{Introduction}

$\mathrm{H}$

ALL thrusters are an electric propulsion technology that is becoming an increasingly attractive option for NASA manned and science missions. With an increased emphasis on higher thrust levels and reduced trip times, the Office of the Chief Technologist (OCT) has taken an interest in high-power Hall thrusters in the range of 20-50 kW. NASA's Glenn Research Center (GRC) has had a long history of developing and testing such highpower Hall thrusters. ${ }^{1-3}$ Due to interest and funding from OCT, these thrusters, in particular the 20-kW NASA$300 \mathrm{M}$ and the 50-kW NASA-457Mv2, are now being revisited and a number of measurements are being taken in order to better understand high-power Hall thruster physics and characterize performance. ${ }^{4-7}$ The purpose of the measurements is three-fold. The first is to provide data that will help characterize thruster performance and efficiency and ultimately lead to the design of a high-power, high-performance Hall thruster with long lifetime. The

\footnotetext{
* Aerospace Engineer, Propulsion and Propellants Branch, 21000 Brookpark Rd., MS 301-3, Member.

${ }^{\dagger}$ Aerospace Engineer, Propulsion and Propellants Branch, 21000 Brookpark Rd., MS 301-3, Member.

* Aerospace Engineer, Propulsion and Propellants Branch, 21000 Brookpark Rd., MS 86-8, Senior Member.

$\S$ Aerospace Engineer, Propulsion and Propellants Branch, 21000 Brookpark Rd., MS 16-1, Member.

** Aerospace Engineer, Propulsion and Propellants Branch, 21000 Brookpark Rd., MS 301-3, Associate Fellow.
} 
second is to provide baseline data on existing thrusters prior to planned modifications that utilize a magneticallyshielded design for long life. ${ }^{8}$ The third purpose is to provide experimental data for validation of ongoing modeling efforts at GRC and the Jet Propulsion Laboratory (JPL).

To accomplish these goals, an electrostatic probe array was deployed to interrogate the near-field plume of the NASA-457Mv2 Hall thruster from approximately $0.1-2$ mean thruster diameters $\left(\mathrm{D}_{\mathrm{T}, \mathrm{m}}\right)$ downstream of the thruster exit plane. Similar measurements have been taken before on the 6-kW H6 Hall thruster at JPL. ${ }^{10,11}$ The probe array consisted of a near-field Faraday probe, a single Langmuir probe, and two emissive probes (one for redundancy). The measurements taken with the Faraday probe are not discussed here as they are the subject of a companion paper. ${ }^{5}$ Measurements at these distances were facilitated with the use of a high-speed linear motion table driven at approximately $250 \mathrm{~mm} / \mathrm{s}$ to minimize residence time in the plume and avoid probe overheating and failure. While data were taken over 14 operating conditions over a wide range of discharge voltages and powers, only four are presented in this paper: 300,400 , and $500 \mathrm{~V}$ at $30 \mathrm{~kW}$ and $500 \mathrm{~V}$ at $50 \mathrm{~kW}$.

The paper is organized as follows: Section II details the vacuum facility, Hall thruster, and the Langmuir and emissive probes used in this study. Section III provides spatial maps of plasma potential and electron temperature in the near-field plume at the four operating conditions mentioned above. Section IV discusses the shape of isothermal lines in the plume, implications of this shape on the plasma adjacent to the magnetic poles, behavior of plasma potential and electron temperature in the very-near-field plume $\left(\leq 0.4 \mathrm{D}_{\mathrm{T}, \mathrm{m}}\right)$, and axisymmetry of the thruster based on measured plasma potential profiles. Section V provides a summary of the conclusions of the study.

\section{Experimental Apparatus}

\section{A. Vacuum Facility}

Testing for this study was performed in Vacuum Facility 5 (VF-5) at NASA GRC. The facility is a 4.6-mdiameter by 18.3 -m-long cylindrical chamber that is equipped with cryogenic surfaces as well as 200.8 -m-diameter oil diffusion pumps. Facility pressure was measured with an exposed hot cathode ionization gauge that was mounted near the test article in order to obtain a more accurate measurement of the backpressure the thruster was exposed to during operation. Facility base pressures of $4.0 \times 10^{-7}$ Torr were routinely achieved. Pressure next to the thruster did not exceed $3.0 \times 10^{-5}$ Torr (corrected for xenon) throughout testing.

\section{B. Test Article and Support Hardware}

The test article for this study was the 50-kW NASA-457Mv2 Hall Thruster. Performance testing of this thruster was completed within VF-5 in 2011, ${ }^{7}$ around the same time the work described in this paper was performed. The NASA-457Mv2 Hall thruster is a nominally $50-\mathrm{kW}$ thruster routinely operated up to $500 \mathrm{~V}$ of discharge voltage and $100 \mathrm{~A}$ of discharge current. It is a higher-fidelity thruster and is based on lessons learned from the laboratory model NASA-457Mv1. Xenon was supplied through commercially available mass flow controllers with an accuracy of $\pm 1 \%$ of the reading. A commercial power supply capable of outputting $2000 \mathrm{~V}$ and $100 \mathrm{~A}$ was used to sustain the discharge. Separate power supplies were used to supply power to the magnets, cathode keeper and heater. The thruster's center-mounted cathode is a laboratory model based on the discharge cathode assembly for NASA's Evolutionary Xenon Thruster (NEXT) and has been used previously on the NASA-300M, 400M and 457Mv1 Hall thrusters. The cathode flow rate was fixed at $8 \%$ of the anode flow rate throughout testing. For this study, the cathode was mounted flush with the thruster exit plane, resulting is slightly increased coupling voltage. This was done so the cathode position was not a limiting factor on the closest approach of probe interrogation. A symmetric magnetic field topology (one that is symmetric about the channel centerline) was used for all operating conditions presented, and the field strength was chosen to maximize anode efficiency as measured by a thrust stand:

$$
\eta_{a}=\frac{T^{2}}{2 \dot{m}_{a} P_{d}}
$$

where $\eta_{a}$ is the anode efficiency, $T$ is the measured thrust, $\dot{m}_{a}$ is the anode mass flow rate, and $P_{d}$ is the discharge power.

\section{Near-field Plume Diagnostics}

This study utilized a multi-probe array comprised of a near-field Faraday probe, a single Langmuir probe, and two emissive probes. The second emissive probe was included for redundancy due to the fragility of this particular type of probe, thus allowing testing to continue after the primary probe failed. The near-field Faraday probe is not discussed here as it is the primary subject of a companion paper. ${ }^{5}$ The probe array used is similar to one used in a 
previous study on the NASA-300M. ${ }^{4}$ Figure 1 shows photographs of the probe array both before and during operation. The emissive probe to the far side of the Faraday probe was used as the primary emissive probe, while the one next to the Langmuir probe was used as a backup once the primary probe failed. Each probe was affixed within a small graphite block using set screws to minimize weight and probe footprint. The graphite mounting block was used to minimize backsputtered products when passing in front of the thruster. The probe tips were mounted approximately $12.5 \mathrm{~cm}$ in front of the graphite block to minimize the overall probe array footprint close to the thruster exit plane. Each probe was spaced approximately $30 \mathrm{~mm}$ apart in the radial direction. The graphite block was mounted onto a triangular frame with a square tube as the primary vertical member. This design was chosen to mimimize weight and motion-induced vibrations while maintaining structural rigidity.
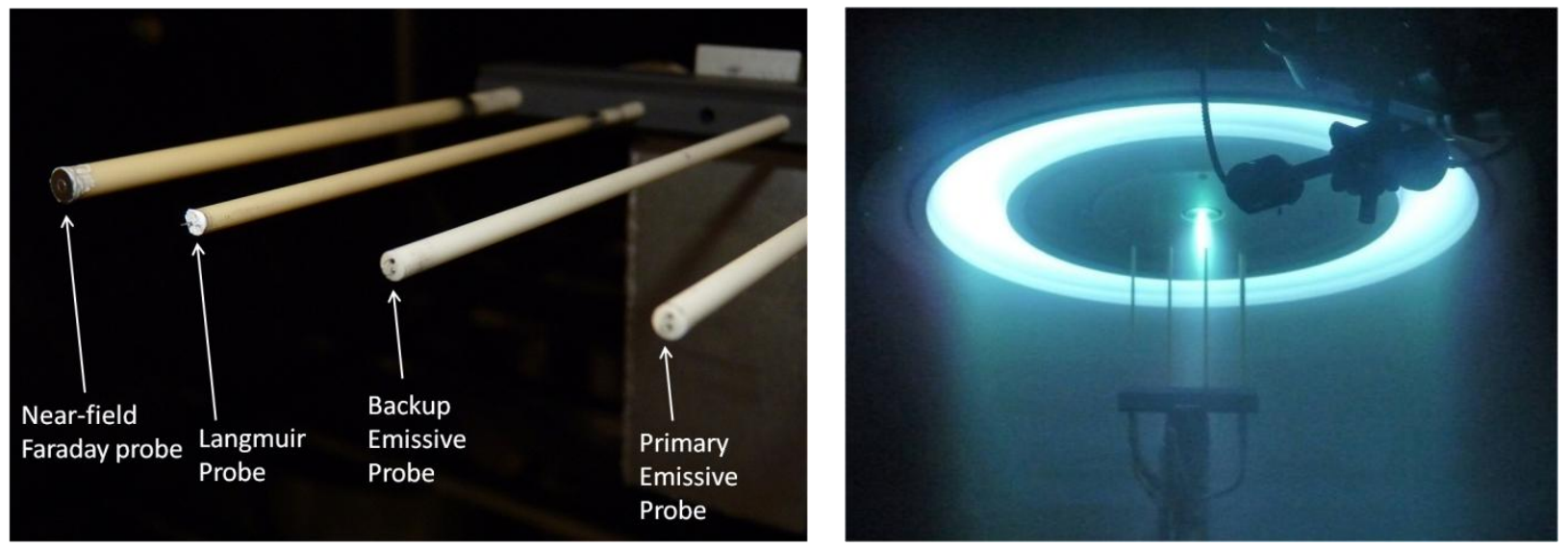

Figure 1. Photographs of the probe array used in this study. Left: Photograph of the probe array showing probe order, taken prior to operation. Right: Probe array passing in front of the NASA-457Mv2 during operation.

The probe array was mounted onto a commercially available two-axis belt-driven motion system. The radial table was operated at high speed, typically $250 \mathrm{~mm} / \mathrm{s}$, to minimize the residence time the probes spent directly in front of the thruster. The probe array was swept from end to end in the radial direction, resulting in data approximately 3 $\mathrm{D}_{\mathrm{T}, \mathrm{m}}$ in either direction from thruster centerline. The axial interrogation grid was chosen to maximize resolution close to the exit plane where large gradients are expected to occur, while gradually stepping down resolution as the probes moved further downstream (see Fig. 2).

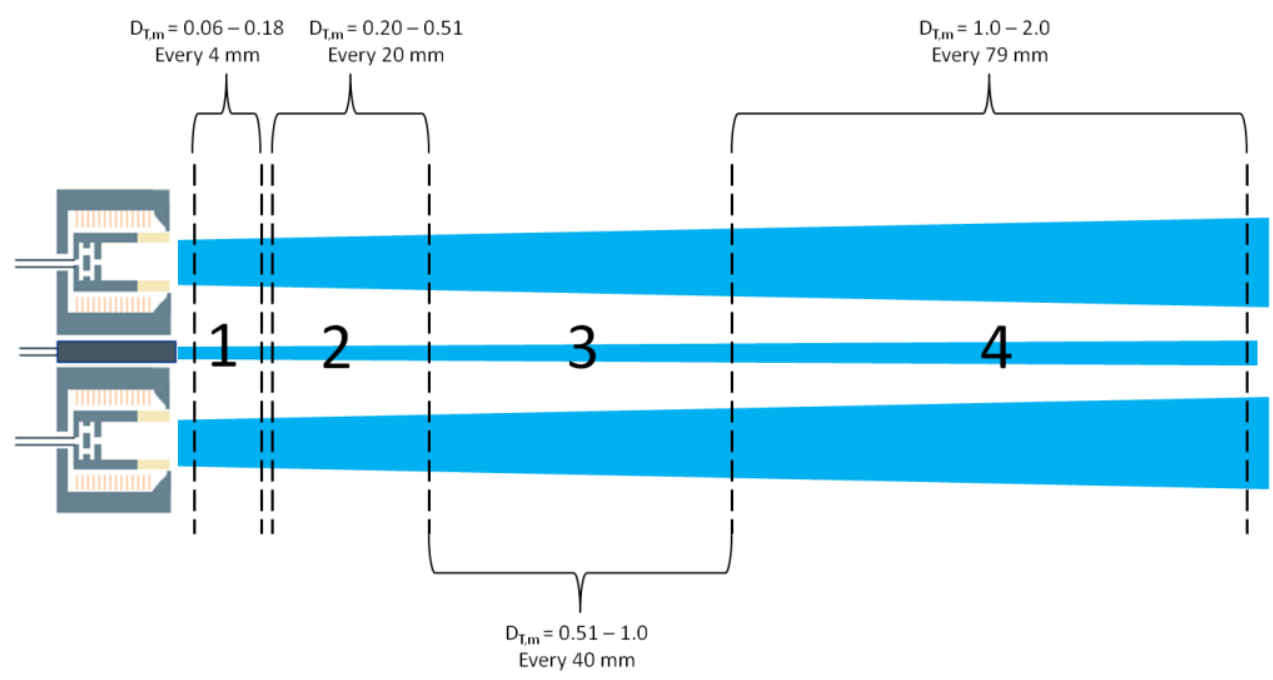

Figure 2. Schematic of the spatial resolution selected in the axial direction, as a function of downstream distance from the exit plane. Resolution becomes coarser as the probes move further downstream and expected gradients become small. Not to scale. 
The following sections detail the probe construction, measurement circuits, and data analysis techniques associated with the single Langmuir probe and emissive probe.

\section{Langmuir Probe}

A single Langmuir probe was used to measure the floating potential and electron temperature in the near-field plume of the NASA-457Mv2. Figure 3 shows a schematic of the probe tip used in this study. The probe itself is comprised of a $0.250-\mathrm{mm}$-diameter pure tungsten wire sleeved within a double-bore alumina tube with an outer diameter of $3.2 \mathrm{~mm}$. The exposed length of the wire was chosen to be $2.0 \mathrm{~mm}$, providing a length-to-diameter-ratio of eight in order to reduce end effects. An identical wire was sleeved in the adjacent bore and encapsulated using high-temperature ceramabond. This "null" probe was biased in an identical way to the active probe, but since it is isolated from the plasma, it can characterize capacitive effects in the electrical line that can be subtracted out in postprocessing. ${ }^{12}$ The majority of the electrical lines leading from the probe wires to the measurement circuit were comprised of shielded coaxial cabling.

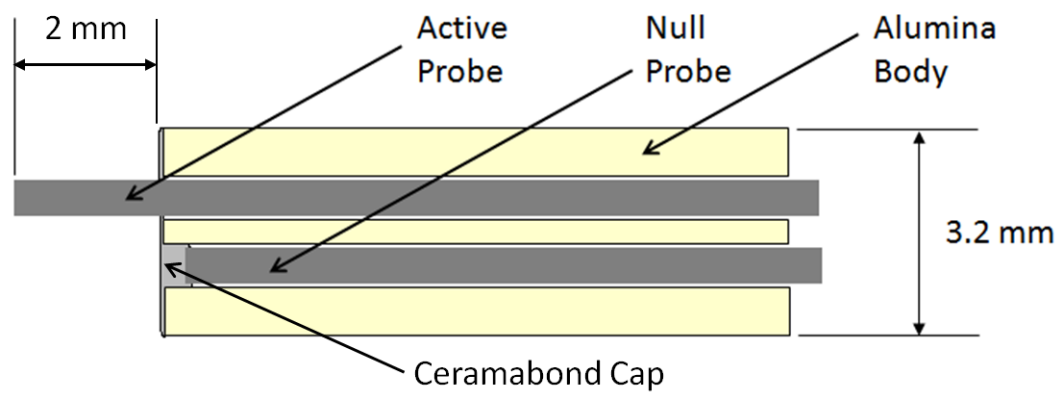

Figure 3. Schematic of the Langmuir probe tip used in this study. An encapsulated "null" probe was used and biased the same way as the active probe to characterize capacitive effects. Not to scale.

Figure 4 shows the electrical circuit used to measure probe currents and voltages from the single Langmuir probe. Two 160- $\Omega, 1-\mathrm{W}$ carbon resistors were used to measure the currents from the active and null Langmuir probes. The voltage signal from each shunt was passed through a voltage-following isolation amplifier before being read by the data acquisition system (DACS) in order to protect the DACS from high commonmode voltages. Blocking diodes were also used in-line with shunts in order to protect the circuitry from large current spikes. Voltage was applied to the probe using a bipolar power supply connected to a function generator. The applied voltage was measured using a voltage divider comprised of $10-\mathrm{M} \Omega$ and $0.83-\mathrm{M} \Omega \quad 0.25-\mathrm{W}$ metal-film resistors, whose voltage signal was also passed through a voltage-following isolation amplifier. For this study, the probe was biased using a

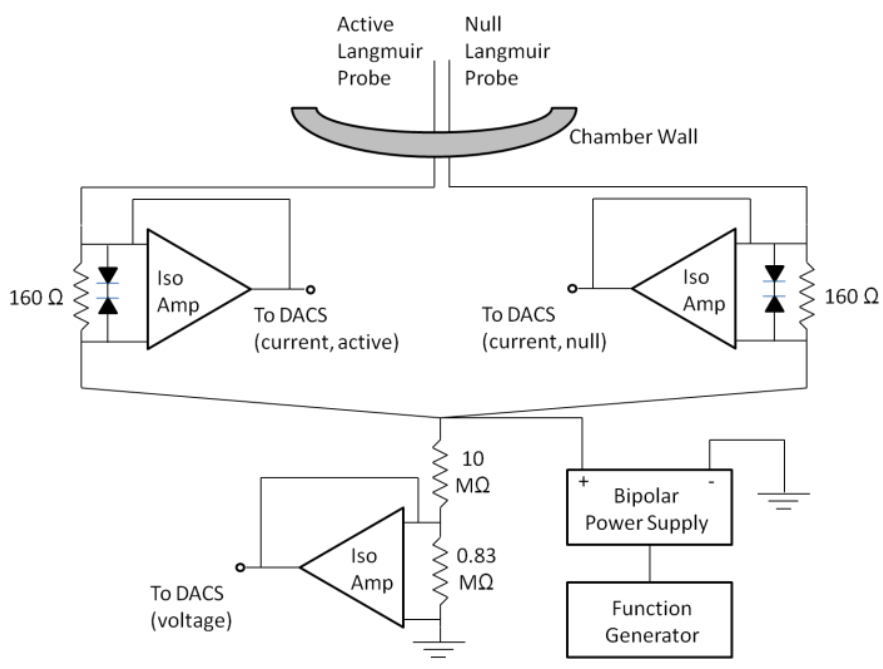

Figure 4. Electrical diagram of the measurement circuit used for the single Langmuir probe.

symmetric triangle wave at a frequency of $125 \mathrm{~Hz}$, well within the $20-\mathrm{kHz}$ bandwidth of the isolation amplifiers. This frequency provided a spatial resolution in the radial direction of $1 \mathrm{~mm}$. The probe voltage range was fixed throughout the study at -95 to $+15 \mathrm{~V}$ with respect to facility ground. Both current and voltage signals were measured using a commercially available 16-bit DACS. The circuit was calibrated both before and after testing and displayed excellent linearity and repeatability. The scan rate was kept constant at $50 \mathrm{kHz}$ per channel, resulting in 200 points per Langmuir probe I-V characteristic. The scan rate was largely dictated by the table speed as the total number of points taken was set at the maximum allowed by the DACS buffer (i.e. 500,000 points). 
Data analysis of the resulting I-V characteristics largely followed simple Langmuir probe theory. ${ }^{13,14}$ The floating potential was found first by determining the probe voltage at which zero net current was collected. The ion current was then subtracted from the probe current and a natural logarithm of the remaining current was plotted against probe voltage. A fit was made using linear regression to the region around the floating potential, whose inverse slope was taken to be the electron temperature in $\mathrm{eV}$. Due to variations in line fits for a given I-V characteristic, uncertainty in the measured electron temperature is taken to be $\pm 15 \%$.

For the the four operating conditions presented in this paper, the null probe appeared to work very well and produced a signal that, once subtracted from the active probe signal, removed significant jumps in measured current where the probe bias ramp switched direction. Erratic behavior in the null probe current seen in certain operating conditions during a similar test on the NASA- $300 \mathrm{M}^{4}$ were not observed in this study. Based on the equation for capacitive current,

$$
I_{\text {cap }}=C \frac{d V}{d t}
$$

the expected response from the null probe when using a triangular wave for the voltage bias is a square wave. In Eq. (2), $I_{\text {cap }}$ is the capacitive current, $C$ is the line capacitance, and $d V / d t$ is the time derivative of the applied voltage. Figure 5 shows the typical measured current signal from the null probe using a symmetric triangular waveform for the probe bias. As evident in the figure, the null probe reproduces the expected square wave response.

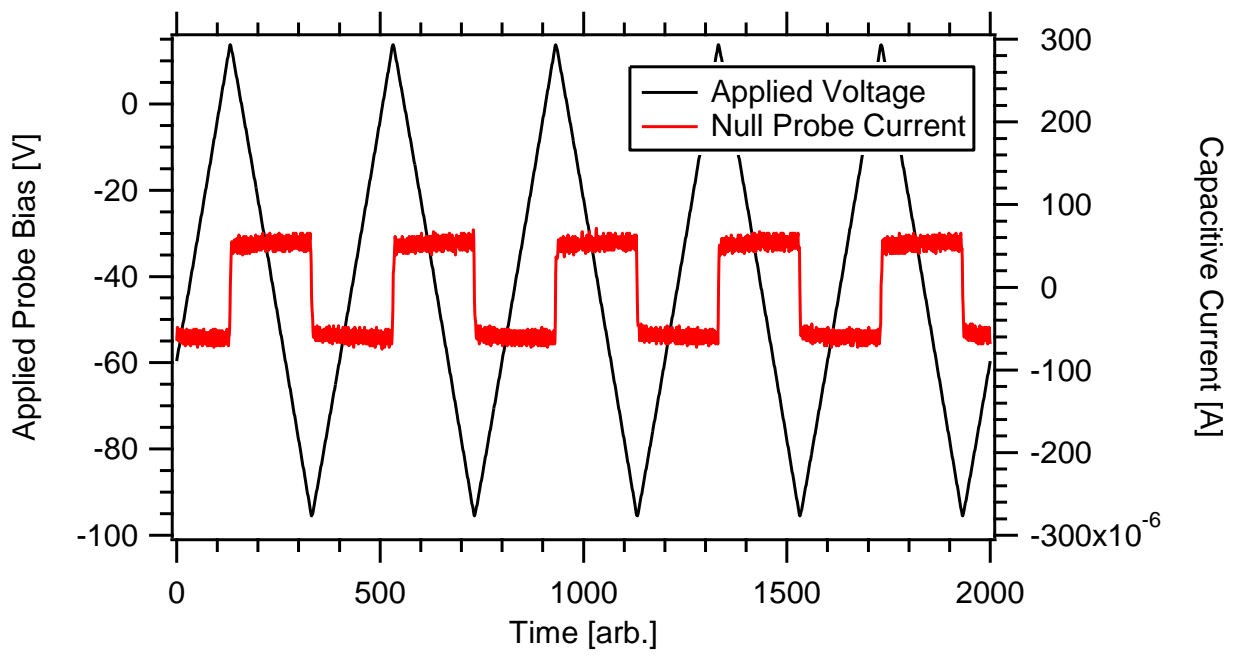

Figure 5. Typical measured current from the null probe using a symmetric triangle waveform for the probe bias. As expected from Eq. (2), the resulting waveform is a square wave.

\section{Emissive Probe}

A floating emissive probe was used in this study to measure the local plasma potential in the near-field plume of the NASA-457Mv2. This particular type of probe has extensive heritage in measuring plasma potential in the nearfield as well as within the channel of Hall thrusters. ${ }^{10,15-17}$ It is an attractive diagnostic due to its relatively simple operation, direct measurement technique, and insensitivity to various non-ideal environmental factors such as nonMaxwellian electrons and presence of magnetic fields. The probe design for this study is based on a previous design by Haas ${ }^{15}$ and later augmented by Linnell ${ }^{16}$ and Reid. ${ }^{17}$ The probe filament was comprised of a 0.102 -mm-diameter $1 \%$ thoriated tungsten wire wrapped into a loop with a radius of curvature of $0.8 \mathrm{~mm}$. This filament was inserted into a double-bore alumina tube with an outer diameter of $3.2 \mathrm{~mm}$. Pure tungsten wire $0.250 \mathrm{~mm}$ in diameter served as lead wires and interfaced with the filament within the alumina tube via an interference "press" fit. Smaller tungsten "filler" wires were placed within the alumina tube to provide better electrical contact and a tighter fit between the filament and lead wires. The final length (distance from tube end to filament tip) of the emissive probe was $1.6 \mathrm{~mm}$ (see Fig. 6). 


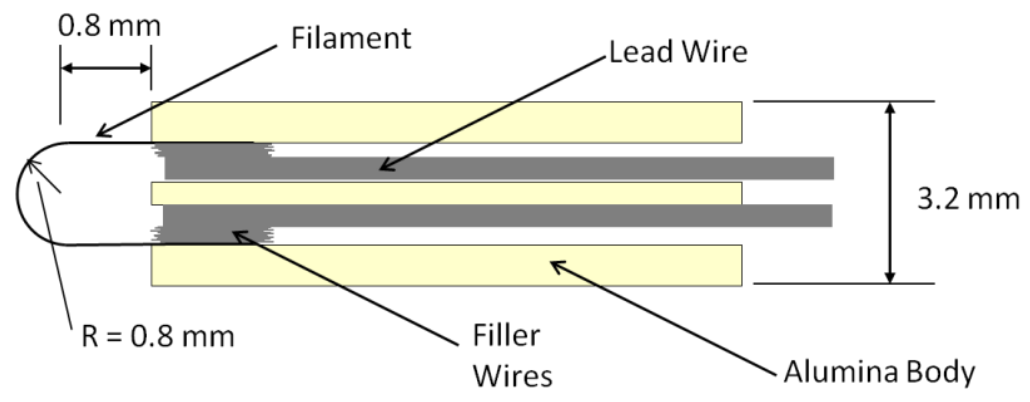

Figure 6. Schematic of the tip of the emissive probe used in this study. Not to scale.

Figure 7 shows the electrical circuit used to measure the floating potential of the emissive probe. A floating power supply was used to supply the necessary current, typically between 2 and $2.5 \mathrm{~A}$, to heat the filament to proper levels of thermionic emission. The potential on both sides of the probe was measured in order to reduce uncertainties associated with the potential drop acoss the filament, which was typically $2.5-4 \mathrm{~V}$. Each potential was measured using a voltage divider comprised of 10 $\mathrm{M} \Omega$ and $0.81-\mathrm{M} \Omega$ 0.25-W metal film resistors. The signal of each side was sent through a voltage-following isolation amplifier before being read by the same DACS that monitored signals from the Langmuir probe circuit. Each voltage divider was calibrated both before and after the study, and displayed excellent linearity and repeatability.

The proper level of filament current was determined by monitoring the probe potential during sweeps across the thruster face at the axial position closest to the exit plane, while slowly increasing filament current with each

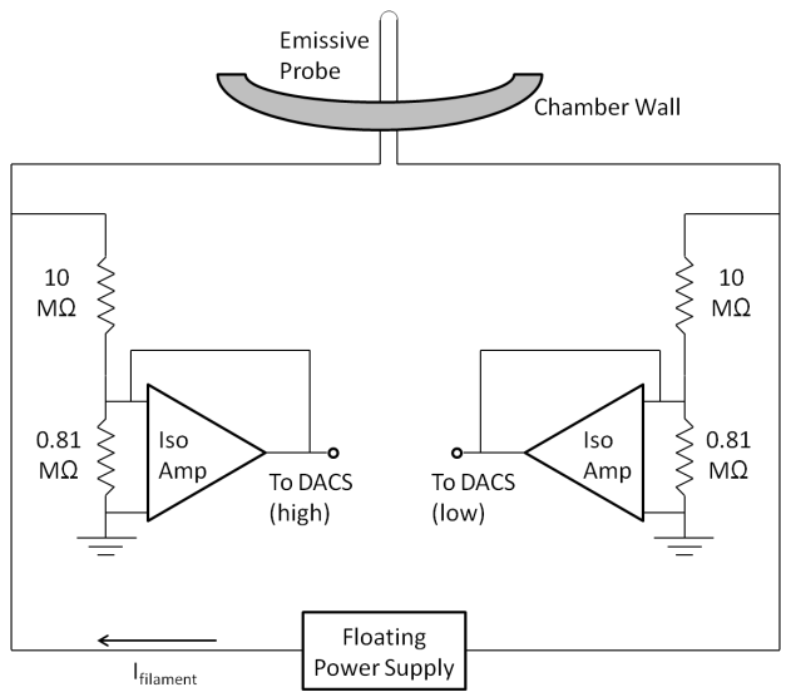

Figure 7. Electrical diagram of the measurement circuit used with the emissive probe in this study.

sweep. The proper level was selected as the minimum amount of current required above which the probe potential did not change. This level of current was then used for the entire spatial domain at the given operating condition. When not in use between radial sweeps, the probe current was set to a low value (where the probe was emitting but not strongly) in order to minimize thermal loading and premature failure of the probe while avoiding large thermal cycling*.

Data reduction comprised of averaging the low and high potential measurements from the DACS. Based on the work from Linnell, ${ }^{16}$ a correction factor of $0.6 T_{e}$ was added to the average measured potential in order to account for space-charge-limited effects at the probe surface. Each radial profile was downsampled to 2000 points, resulting in a spatial resolution of approximately $1 \mathrm{~mm}$. This was done to control the large data sets resulting from the $50 \mathrm{kHz}$ sampling rate dictated by the Langmuir probe data collection.

\section{Results}

An electrostatic probe array was used to measure floating potential, plasma potential, and electron temperature in the near-field plume of the NASA-457Mv2. Four of the operating conditions tested are presented in this paper: 300 $\mathrm{V}, 400 \mathrm{~V}$, and $500 \mathrm{~V}$ at $30 \mathrm{~kW}$ and $500 \mathrm{~V}$ at $50 \mathrm{~kW}$. While the interrogation zone included up to $3 \mathrm{D}_{\mathrm{T}, \mathrm{m}}$ radially away from thruster centerline, only data within $\pm 1 \mathrm{D}_{\mathrm{T}, \mathrm{m}}$ is presented here. This is because plasma properties were found to have negligible gradients far off-axis. Furthermore, the data in this region were more susceptible to noise due to smaller signals resulting from low plasma density. Spatial mapping of the plasma potential and electron temperature are presented below.

*Personal Communication (email) with D.M. Goebel. 


\section{A. Plasma Potential}

Despite the use of a backup emissive probe to allow for additional measurements after the primary probe failed, data could still not be obtained at all operating conditions tested prior to probe failure. Therefore, only plasma potentials at $300 \mathrm{~V}$ and $400 \mathrm{~V}$ and $30 \mathrm{~kW}$ are presented here; probe failure occurred prior to testing at $500 \mathrm{~V}$ discharge voltage. Figure 8 shows the contour maps of measured plasma potential at 300 and $400 \mathrm{~V}, 30 \mathrm{~kW}$. All reported plasma potentials are with respect to cathode potential - the measured potential with respect to facility ground has been corrected with the measured cathode-to-ground potential, typically between -5 and $-10 \mathrm{~V}$. Values below $10 \mathrm{~V}$, typically near the center-mounted cathode, have been removed from the contour maps. Due to the extremely high current densities in this region, it is unlikely the emissive probe was emitting strongly enough to properly float up to plasma potential. Attempts to heat the probe filament enough to properly measure potentials near the cathode would most likely have caused probe failure.
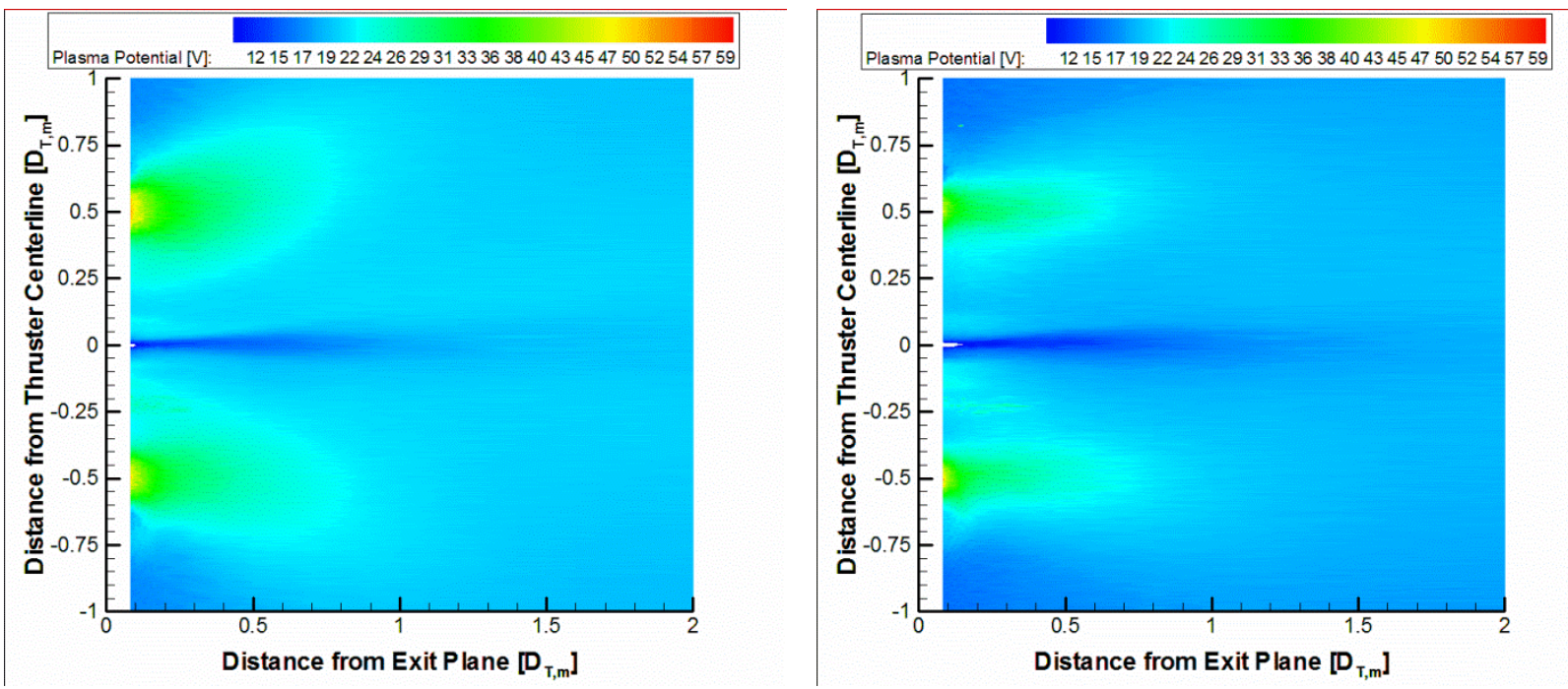

Figure 8. Plasma potential contours in the near-field plume of the NASA-457Mv2. Left: $300 \mathrm{~V}$ at $30 \mathrm{~kW}$. Right: $400 \mathrm{~V}$ at $30 \mathrm{~kW}$. The acceleration zone for both conditions appears to be contained within $0.4 \mathrm{D}_{\mathrm{T}, \mathrm{m}}$ of the thruster exit plane. All reported potentials are with respect to cathode potential.

Figure 8 shows that most of the near-field plume is at a fairly uniform potential of approximately $20-25 \mathrm{~V}$ above cathode potential for both operating conditions. Most of the acceleration zone appears to be contained within 0.4 $\mathrm{D}_{\mathrm{T}, \mathrm{m}}$ of the thruster exit plane. The maximum measured plasma potentials at $0.08 \mathrm{D}_{\mathrm{T}, \mathrm{m}}$ from the exit plane are $52 \mathrm{~V}$ and $55 \mathrm{~V}$ at $300 \mathrm{~V}, 30 \mathrm{~kW}$ and $400 \mathrm{~V}, 30 \mathrm{~kW}$ respectively. This confirms that while such near-field studies provide critical information regarding the plasma downstream of the exit plane, the majority of the acceleration zone lies upstream of this region and requires internal measurements to fully capture it. From Fig. 8, the plasma potential appears to drop off radially from channel centerline more rapidly at $400 \mathrm{~V}$ compared to $300 \mathrm{~V}$. This is an indication that the plasma is more concentrated around channel centerline at $400 \mathrm{~V}$, thus implying the beam is more collimated. This trend is confirmed with ion current density measurements made in the near-field at these conditions. ${ }^{5}$ Comparisons between the two measured sides of the thruster as well as further discussions regarding the acceleration zone can be found in Section IV.

\section{B. Electron Temperature}

Figure 9 shows the contour maps of measured electron temperature downstream of the exit plane at four operating conditions. All four maps have been plotted on the same scale for direct comparisons. Based on these contour maps, the isothermal lines appear to have similar shape and structure in the near-field plume across all four operating conditions. The source and implications of this structure are further discussed in Section IV. For all four operating conditions the region of high-temperature is contained within $0.25 \mathrm{D}_{\mathrm{T}, \mathrm{m}}$ from the thruster exit plane. The remainder of the near-field plume is at roughly constant temperature ranging from $2-5 \mathrm{eV}$. The maximum measured electron temperatures at $0.06 \mathrm{D}_{\mathrm{T}, \mathrm{m}}$ from the thruster exit plane are: $26 \mathrm{eV}$ for $300 \mathrm{~V}$ at $30 \mathrm{~kW}, 24 \mathrm{eV}$ for $400 \mathrm{~V}$ at $30 \mathrm{~kW}, 27 \mathrm{eV}$ for $500 \mathrm{~V}$ at $30 \mathrm{~kW}$, and $32 \mathrm{eV}$ for $500 \mathrm{~V}$ at $50 \mathrm{~kW}$. While higher electron temperatures are expected at higher discharge voltages due to increased Ohmic heating, the highest electron temperature in the near- 
field plume is also affected by the shifting of the ionization and acceleration zones with operating condition. As will be discussed in Section IV, these temperatures will have a strong effect on the behavior near surfaces adjacent to the channel exit (i.e. the channel walls and magnetic poles).

It should be mentioned that erratic behavior was observed in the measured electron temperature at two locations within the plume: at $-0.25 \mathrm{D}_{\mathrm{T}, \mathrm{m}}$ in the radial direction from $0.06-0.5 \mathrm{D}_{\mathrm{T}, \mathrm{m}}$ in the axial direction; and $0.75-1 \mathrm{D}_{\mathrm{T}, \mathrm{m}}$ in the radial direction, from $0.3-1.8 \mathrm{D}_{\mathrm{T}, \mathrm{m}}$ in the axial direction. These zones are most apparent in the electron temperature contour at $500 \mathrm{~V}$ and $50 \mathrm{~kW}$. Within these regions the measured floating potential was lower than expected based on spatially neighboring values as well as the general shape of I-V characteristics. For this reason, the analysis of the resulting data was difficult to automate, resulting in erroneous calculated electron temperatures. While data analysis techniques were slightly altered to better analyze data in this region, the effect appeared to worsen as testing continued; thus, the erratic behavior is most evident at $500 \mathrm{~V}$ conditions which were interrogated later in the study. It is unclear at this time what the source of the behavior is; data within these regions is questionable and should not be interpreted as real. It should be emphasized, however, that the erratic behavior was limited to these zones and does not affect analysis and interpretation of the remaining data.
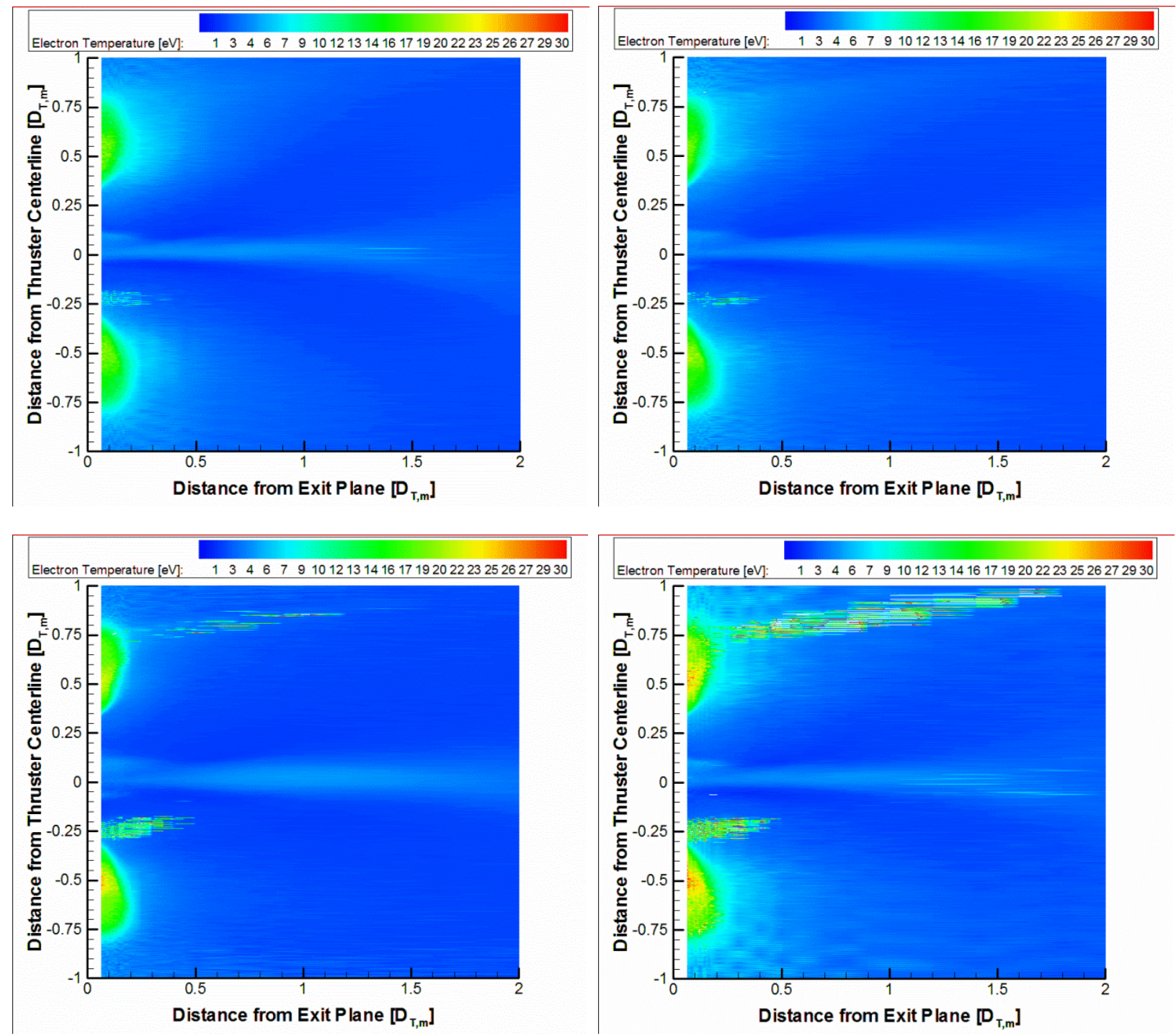

Figure 9. Contour plots of measured electron temperature in the near-field of the NASA-457Mv2. Top Left: $300 \mathrm{~V}$ at 30 kW. Top Right: $400 \mathrm{~V}, 30 \mathrm{~kW}$. Bottom Left: $500 \mathrm{~V}, 30 \mathrm{~kW}$. Bottom Right: $500 \mathrm{~V}, 50 \mathrm{~kW}$. Isothermal lines appear to have similar structure across all four operating conditions. 


\section{Discussion}

An electrostatic probe array was used to measure the local floating potential, plasma potential, and electron temperature in the near-field plume of the NASA-457Mv2. As shown in Section III, the high-temperature region and acceleration zones were found to be limited to $0.25 \mathrm{D}_{\mathrm{T}, \mathrm{m}}$ and $0.4 \mathrm{D}_{\mathrm{T}, \mathrm{m}}$ from the thruster exit plane, respectively. The isothermal lines were also shown to exhibit a distinct structure that was found to be similar across all four operating conditions presented. Based on these results, four points will be discussed in this section. The first is a deeper look at the structure of isothermal lines and its origin. Second, implications of the isothermal line structure on behavior near surfaces adjacent to the channel exit will be discussed. Third, the acceleration zone and hightemperature regions in the very-near-field plume (here defined as $\leq 0.4 \mathrm{D}_{\mathrm{T}, \mathrm{m}}$ ) will be looked at in more detail. Lastly, due to the nature of the interrogation zone, symmetry between the two measured sides of the thruster will be briefly discussed.

\section{A. Structure of Isothermal Lines}

As seen in Section III, isothermal lines in the near-field plume were found to exhibit similar structure across a wide range of discharge voltages and powers. This behavior was also observed in prior measurements on the NASA-300M Hall thruster. ${ }^{4}$ In order to analyze this structure further, radial profiles of the electron temperature were plotted at $0.06 \mathrm{D}_{\mathrm{T}, \mathrm{m}}$ from the exit plane for all four operating conditions (see Fig. 10). The erratic values of temperature at a radial position of $-0.25 \mathrm{D}_{\mathrm{T}, \mathrm{m}}$, previously discussed in Section III, were omitted for clarity. Figure 10 shows that while the magnitudes of the electron temperature change with operating condition, all the profiles exhibit a similar shape. The maximum temperature tended to occur at channel centerline $\left( \pm 0.5 \mathrm{D}_{\mathrm{T}, \mathrm{m}}\right)$, while falling off more rapidly moving radially inward compared to moving radially outward. This similiarity in structure is more evident when the profiles are non-dimensionalized by the maximum measured value at each operating condition, as seen in Fig. 11.

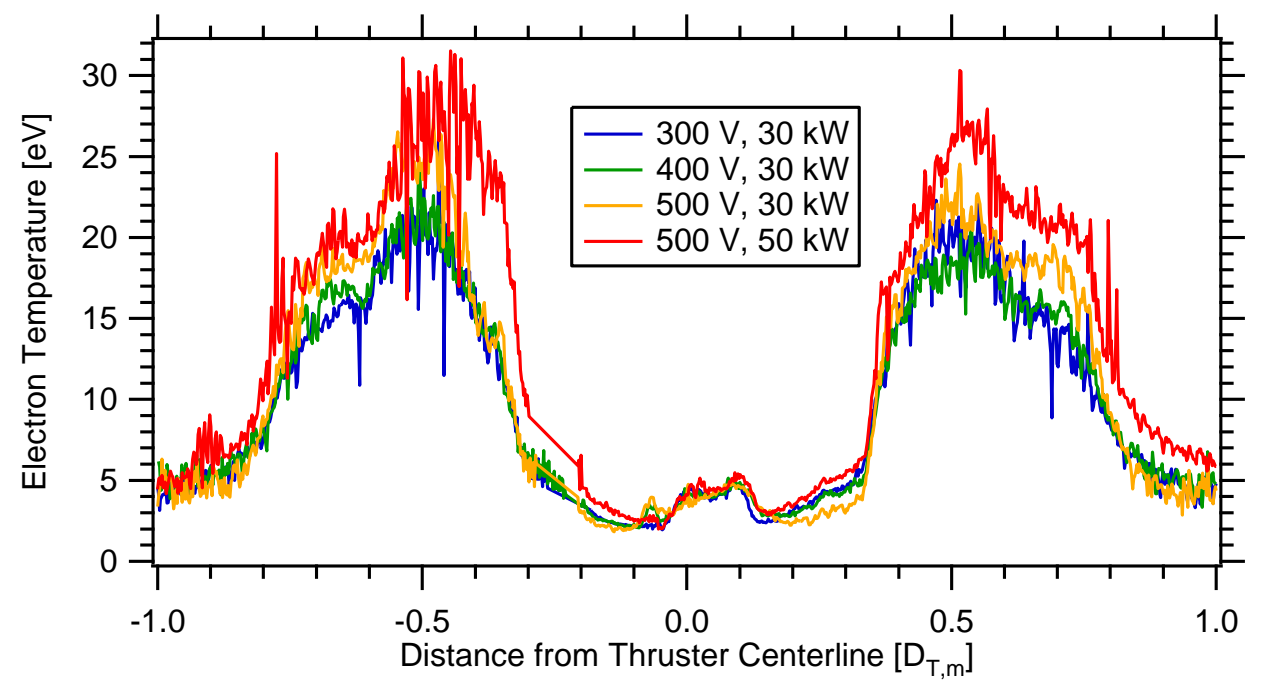

Figure 10. Radial profiles of measured electron temperature at $0.06 \mathrm{D}_{\mathrm{T}, \mathrm{m}}$ from the thruster exit plane. While there are differences in magnitude across operating conditions, all the profiles exhibit a similar shape. 


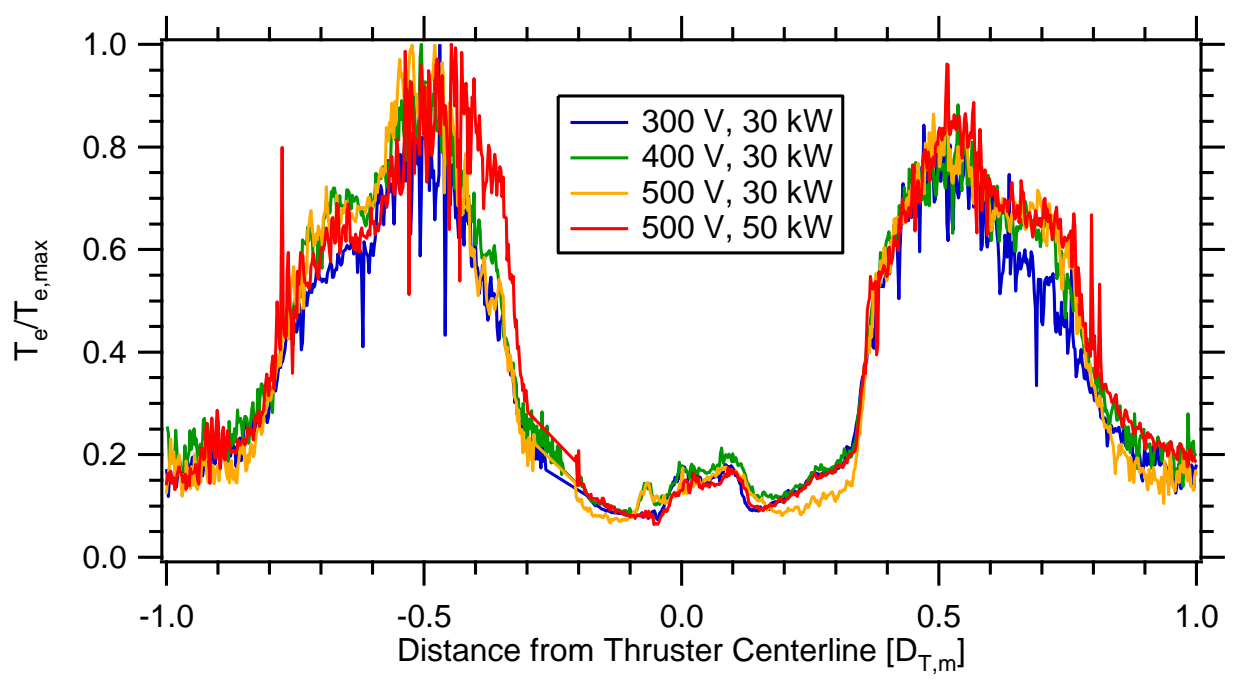

Figure 11. Radial profiles of measured electron temperature at $0.06 D_{T, m}$ from the thruster exit plane, nondimensionalized by the maximum measured value at a given operating condition. Once normalized, the profiles appear to collapse onto each other, indicating a similar structure across operating conditions.

The lobe-like structure seen in the electron temperature contour maps of Fig. 9 is strongly reminiscent of the magnetic field topology in the near-field of typical annular-geometry Hall thrusters. Figure 12 compares the magnetic field topology of the NASA-173Mv1,${ }^{18}$ which is similar to the topology of the NASA-457Mv2 but is not restricted for public release, to the measured electron temperature contours at $500 \mathrm{~V}$ and $30 \mathrm{~kW}$. As evident in the figure, the isothermal lines appear to exhibit the same shape as typical magnetic field lines in the near-field plume. Based on the apparent universal structure across operating conditions and the fact that the magnetic field topology was not changed throughout the study, the data strongly suggest that isothermal lines follow magnetic field lines in the near-field plume. This is further experimental evidence for computational studies that frequently assume that the electron temperature is constant along magnetic field lines. While this assumption appears to be true in the nearfield, it doesn't necessarily indicate the same behavior outside the interrogation zone, such as within the channel. Internal measurements currently being made at GRC will offer further insights into the correlation between electron temperature and magnetic field lines within the channel.
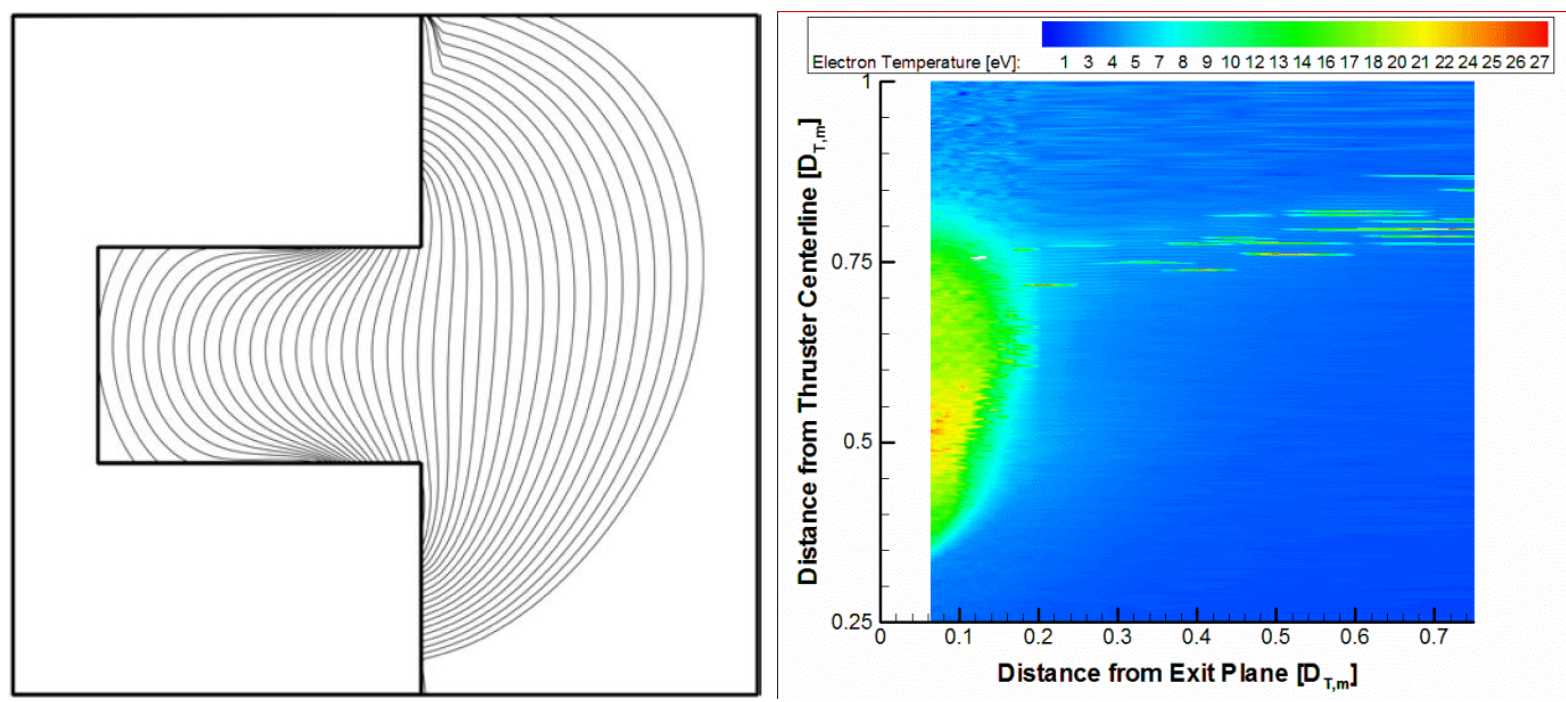

Figure 12. Comparison of the magnetic field topology of the NASA-173Mv1 ${ }^{18}$ (left) to the measured electron temperature contours in the near-field of the NASA-457Mv2 at $500 \mathrm{~V}$ and $30 \mathrm{~kW}$ (right). The isothermal lines appear to have a very similar structure to the magnetic field lines. 


\section{B. Behavior Near Surfaces Adjacent to Channel Exit}

The previous section discussed how the isothermal lines in the near-field plume exhibited a similar shape to magnetic field lines. This distinctive shape has implications for the behavior of potentials and sheaths at surfaces adjacent to the channel exit, such as the channel walls and magnetic poles. Due to the distinct shape, the magnetic field lines appear to draw the high-temperature region downstream of the channel towards these adjacent surfaces. However, results from Section III showed that the plasma potential falls off fairly rapidly in the radial direction away from channel centerline. This falloff is also correlated with a significant drop in plasma density in these regions. Therefore, the plasma near these surfaces is characterized by low density, low plasma potential, and high temperature. The combination of low plasma potential and high electron temperature creates a very low floating potential in these regions. Figure 13 shows a contour map of floating potential in the near-field plume at $500 \mathrm{~V}$ and $50 \mathrm{~kW}$. All values of floating potential are referenced with respect to facility ground. The contour map clearly shows that regions adjacent to the radial channel bounds near the thruster exit plane are characterized by extremely low floating potentials, some approaching $-90 \mathrm{~V}$. Similar behavior was observed in the near-field plume of the NASA-300M. ${ }^{4}$

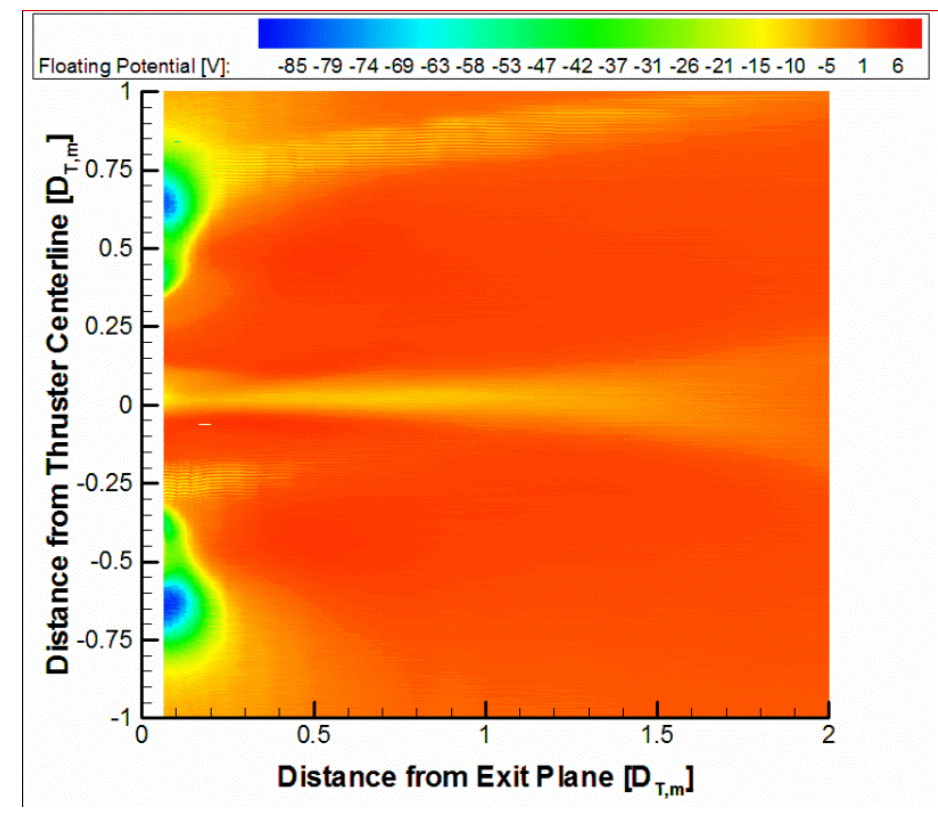

Figure 13. Contour map of measured floating potential in the near-field plume at $500 \mathrm{~V}$ and $50 \mathrm{~kW}$. Regions to the sides of the channel near the exit plane are characterized by very low floating potentials approaching $-90 \mathrm{~V}$ with respect to facility ground.

To illustrate this behavior further, the radial profiles of the floating potential at $0.06 \mathrm{D}_{\mathrm{T}, \mathrm{m}}$ from the exit plane are plotted for the four operating conditions presented (see Fig. 14). Drops in floating potential are seen on both sides of channel centerline $\left( \pm 0.5 \mathrm{D}_{\mathrm{T}, \mathrm{m}}\right)$, with larger drops occurring at higher voltages. This trend with voltage is the result of higher observed temperatures in the near-field plume at $500 \mathrm{~V}$, as discussed in Section III. Furthermore, the drop on the outer side of the channel is greater than the drop on the inner side. The reason for this structure is due to the magnetic field topology which shapes the isothermal lines. On the inner side, the magnetic field lines are more highly concentrated, making the electron temperature drop off more rapidly in the radial direction - this feature can be seen in Fig. 10. Conversely, the magnetic field lines are more spread out along the outer side, allowing for a more gradual dropoff in temperature. This more gradual decrease allows the plasma potential and number density to decrease more from values at channel centerline, thus creating a larger zone that is characterized by low potential, low number density, and high electron temperature. 


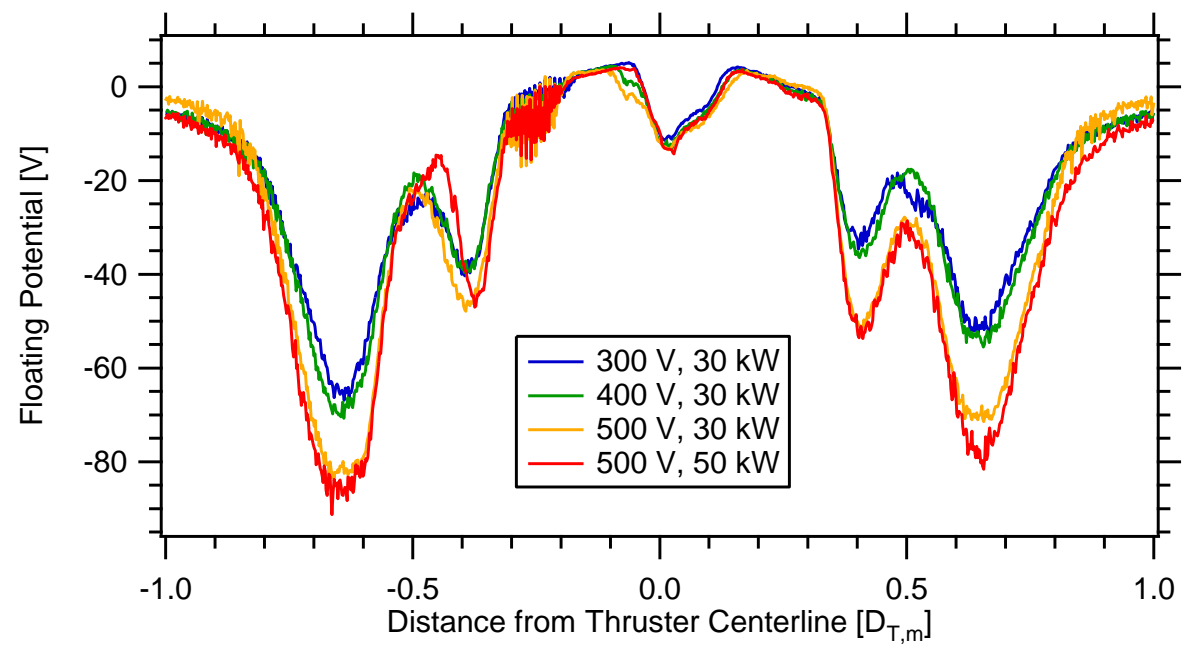

Figure 14. Radial profiles of the measured floating potential at $0.06 \mathrm{D}_{\mathrm{T}, \mathrm{m}}$ from the exit plane. All values are with respect to facility ground. The floating potential dips adjacent to the channel bounds are deeper for the $500 \mathrm{~V}$ conditions, which are characterized by higher temperatures in the near-field plume.

The implications of this behavior, if any, on thruster performance are currently unknown. The presence of a lowdensity, high-temperature plasma in the vicinity of the channel walls and magnetic poles indicates that the sheaths formed on these surfaces will be thick with large potential drops. Despite this, the power loss to these surfaces is not expected to be large due to the relatively low plasma density in these regions. This trend, however, is worth noting from a purely experimental point of view. Since this behavior was seen in prior testing on the NASA-300M, ${ }^{4}$ both the Langmuir probe and Faraday probe were biased to lower values in this study to prepare for the expected drop in floating potentials in these regions. Future tests performed in the near-field of Hall thrusters should also take this behavior into account if proper data (i.e. probes biased appropriately) are to be taken in these regions.

\section{Analysis of the Very-Near-Field Plume}

Section III discussed how the high-electron-temperature region was limited to $0.25 \mathrm{D}_{\mathrm{T}, \mathrm{m}}$ from the exit plane while the acceleration zones at 300 and $400 \mathrm{~V}, 30 \mathrm{~kW}$ were limited to $0.4 \mathrm{D}_{\mathrm{T}, \mathrm{m}}$ from the exit plane. These regions together will be referred to as the very-near-field plume. The sharp rises in electron temperature and plasma potential as the exit plane is approached will be analyzed in more detail below.

Figures 15 and 16 show the axial profiles of plasma potential and electron temperature along channel centerline $\left(-0.5 \mathrm{D}_{\mathrm{T}, \mathrm{m}}\right)$ for the operating conditions presented in Section III. The distance is plotted on a log scale to better illustrate the sharp rise in properties as the thruster exit plane is approached. As mentioned in Section III, the maximum measured potential, at a distance of $0.08 \mathrm{D}_{\mathrm{T}, \mathrm{m}}$ from the exit plane, is $52 \mathrm{~V}$ at $300 \mathrm{~V}$ and $55 \mathrm{~V}$ at $400 \mathrm{~V}$. Assuming that the plasma potential reaches anode potential deep within the channel, these maximum measured potentials corresponds to $11 \%$ and $9 \%$ of the total potential rise at 300 and $400 \mathrm{~V}$, respectively. This result is unexpected given the relatively high electron temperatures measured at these locations. At $0.08 \mathrm{D}_{\mathrm{T}, \mathrm{m}}$, the electron temperature rose to $19 \mathrm{eV}$ at both 300 and $400 \mathrm{~V}$ discharges. It has been well-established from previous measurements that the electron temperature increases fairly linearly with local plasma potential in Hall thrusters, with typical reported values of $0.07-0.16 \mathrm{eV} / \mathrm{V}$ of potential. ${ }^{16,17,19}$ However, the data in this study show that the average value in the near-field plume of the NASA-457Mv2 is 0.52 and $0.46 \mathrm{eV} / \mathrm{V}$ at $300 \mathrm{~V}$ and $400 \mathrm{~V}$, respectively. An elevated value of $0.24 \mathrm{eV} / \mathrm{V}$ was also found for the NASA-300M at $500 \mathrm{~V}$ and $20 \mathrm{~kW} .{ }^{4}$ The cause of this apparent rise in heating is presently unknown. One explanation is that electron heating is more effective in the near-field plume and drops within the channel due to additional energy losses associated with the channel walls. ${ }^{19}$ However, due to the limited data set and the fact that only $\sim 10 \%$ of the acceleration zone was captured, additional data taken internal to the channel is required to fully understand the relationship between electron temperature and plasma potential in the NASA-457Mv2. 


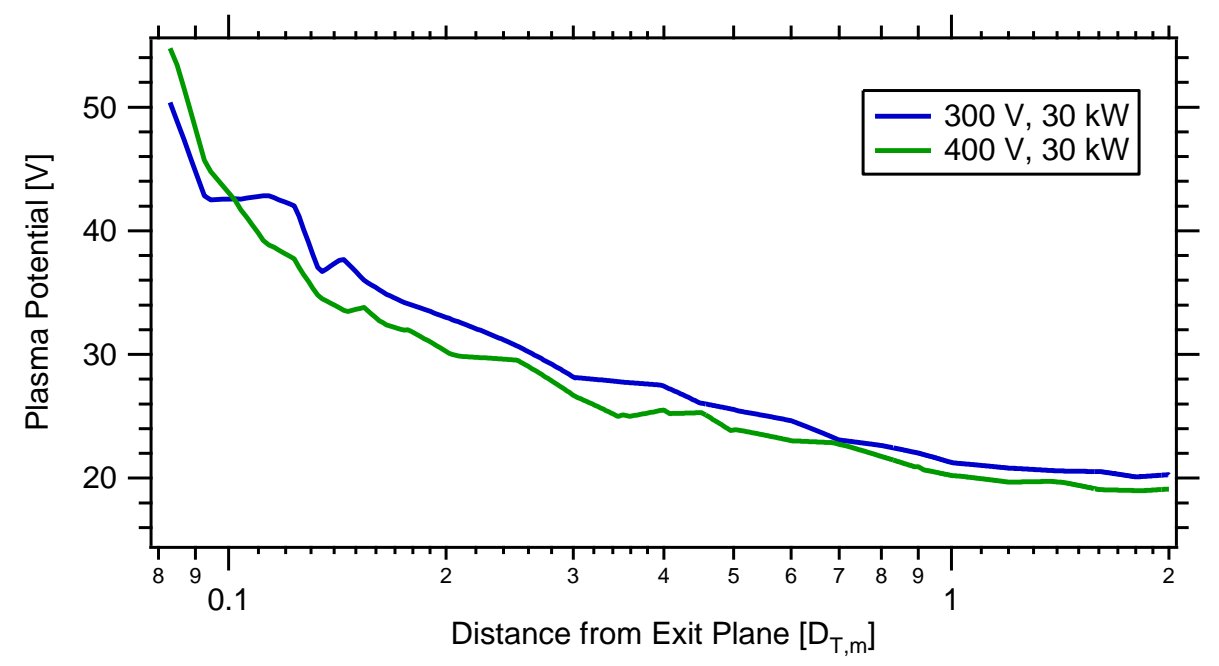

Figure 15. Axial profiles of plasma potential along channel centerline $\left(-0.5 \mathrm{D}_{\mathrm{T}, \mathrm{m}}\right)$ at 300 and $400 \mathrm{~V}, 30 \mathrm{~kW}$. Distance is plotted on a log scale to better illustrate the sharp rising occurring near the thruster exit plane.

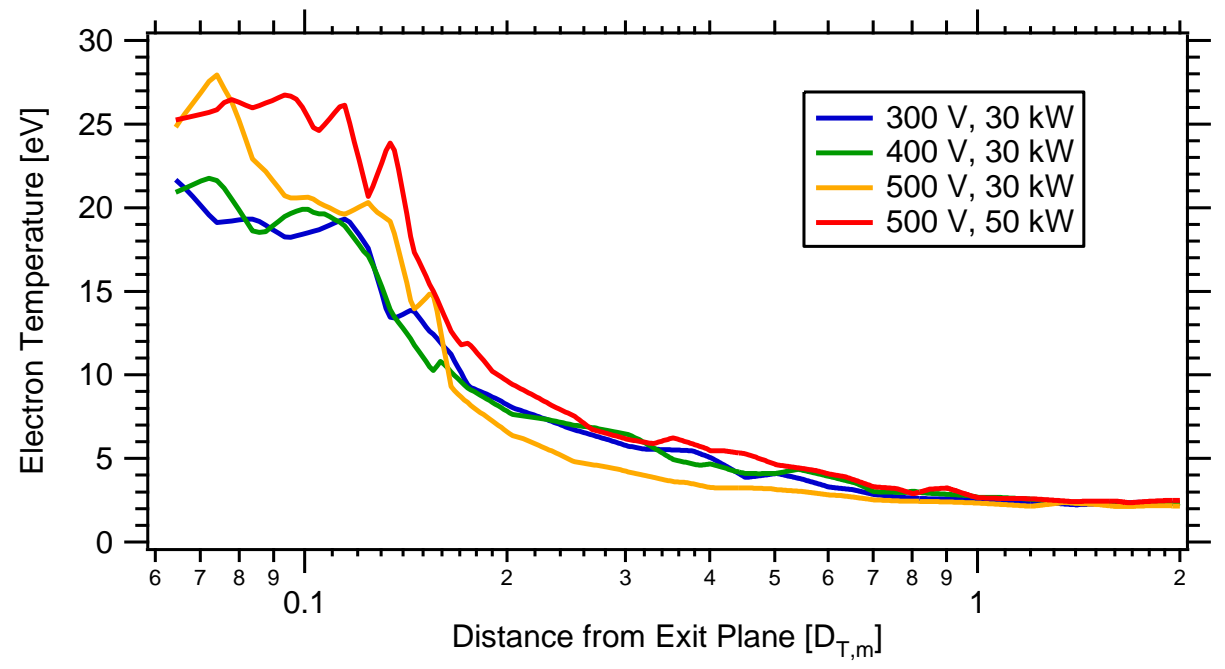

Figure 16. Axial profiles of electron temperature at channel centerline $\left(-0.5 D_{T, m}\right)$ for the four operating conditions presented in this paper. The distance is plotted on a log scale to better illustrate the sharp rise in temperature near the thruster exit plane.

Assuming that the maximum electron temperature is approximately $10 \%$ of the discharge voltage, ${ }^{15}$ at $0.06 \mathrm{D}_{\mathrm{T}, \mathrm{m}}$ from the exit plane the temperature has reached: $72 \%$ of its maximum at $300 \mathrm{~V}, 30 \mathrm{~kW} ; 52 \%$ of its maximum at 400 $\mathrm{V}, 30 \mathrm{~kW} ; 50 \%$ of its maximum at $500 \mathrm{~V}, 30 \mathrm{~kW}$; and $51 \%$ of its maximum at $500 \mathrm{~V}, 50 \mathrm{~kW}$. Given how close these values are to each other and the fact that the axial profiles shown in Fig. 16 appear to have a similar structure, these profiles were non-dimensionalized by the maximum measured value at each operating condition and are compared in Fig. 17. With the possible exception of $500 \mathrm{~V}, 30 \mathrm{~kW}$, the profiles of electron temperature appear to exhibit a similar shape across operating conditions, despite large differences in discharge voltage and power level. This similarity in shape is unexpected since these profiles are expected to be influenced by the length and position of the acceleration zone, which should change with operating condition. ${ }^{17,19}$ However, these results are consistent with the similarity in radial profiles seen in Fig. 11, since the axial and radial profiles are connected via the magnetic field topology which shapes isothermal lines. Once again, this similarity could exist only in the near-field and/or due to the limited data set, and additional measurements internal to the channel will be required to better understand the electon temperature behavior in the NASA-457Mv2. 


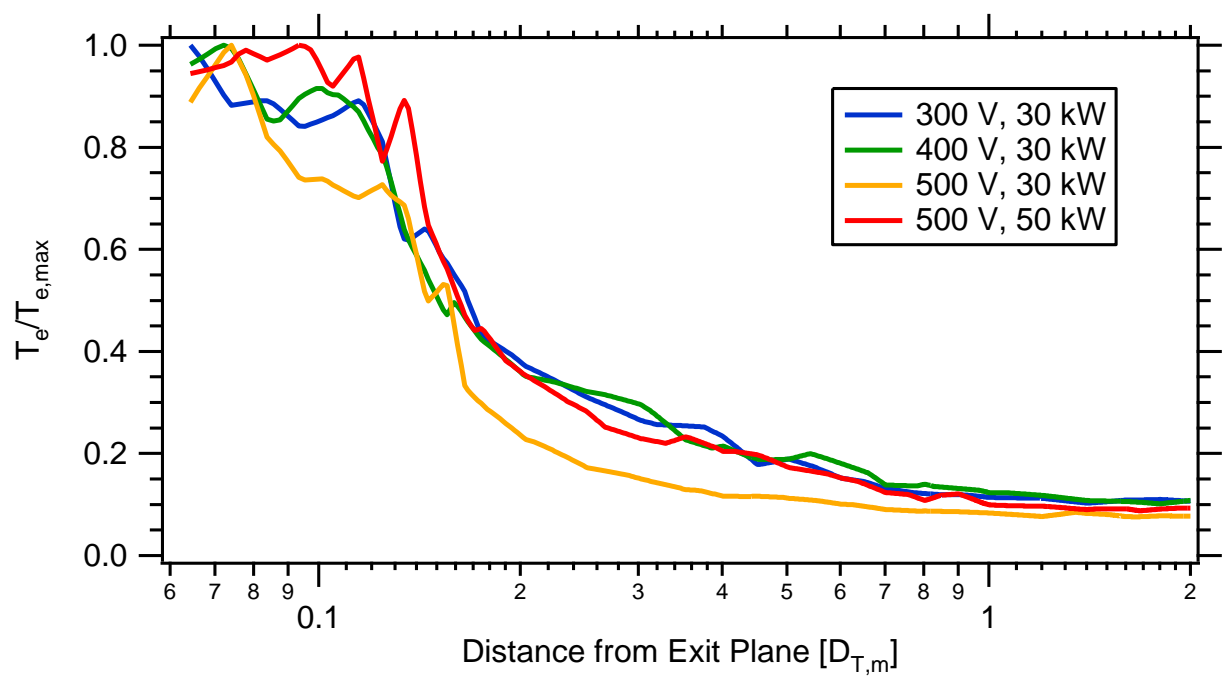

Figure 17. Axial profiles of electron temperature at channel centerline $\left(-0.5 D_{T, m}\right)$, non-dimensionalized by the maximum measured temperature along each profile. There appears to be similarity in shape across operating conditions despite changes in discharge voltage, power, and flow rate.

\section{Symmetry between Thruster Sides}

Since both sides of the thruster were interrogated in this study, comparing the two sides is worthwhile in order to verify the frequent assumption of axisymmetry. Figure 18 shows the radial profiles of measured plasma potential at $0.08 \mathrm{D}_{\mathrm{T}, \mathrm{m}}$ from the exit plane for 300 and $400 \mathrm{~V}$ operation at $30 \mathrm{~kW}$. The figure clearly shows that while the two sides of the thruster are very similar, they do not exhibit perfect axisymmetry. At $300 \mathrm{~V}$, the 9 o'clock position $(-0.5$ $\left.\mathrm{D}_{\mathrm{T}, \mathrm{m}}\right)$ has a peak potential of $50 \mathrm{~V}$ while the 3 o'clock position $\left(+0.5 \mathrm{D}_{\mathrm{T}, \mathrm{m}}\right)$ has a peak potential of $52 \mathrm{~V}$. Similarly, at $400 \mathrm{~V}$, the $9 \mathrm{o}$ 'clock position has a peak plasma potential of $55 \mathrm{~V}$ while the 3 o'clock position has a peak plasma potential of $48 \mathrm{~V}$. Additional information can be found by comparing the axial profiles of plasma potential along channel centerline at each clocked position (see Fig. 19). Once again, while the two clocked positions do not exhibit identical behavior, they are highly similar. Better agreement can be obtained between the axial profiles if one clocked position was shifted approximately $0.01 \mathrm{D}_{\mathrm{T}, \mathrm{m}}$. A similar result was found in the near-field study performed on the NASA-300M. ${ }^{4}$ However, plasma potential was measured at only one operating condition in that study. The cause of the asymmetry was therefore inconclusive on whether the shift was due to thruster asymmetry or a slight motion table misalignment. Based on Fig. 19, since the required axial shift for each operating condition is in opposite directions, the slight asymmetry observed here is not due to a systematic error such as table misalignment. Thus, the thruster acceleration profiles appear to be symmetric to within $\pm 0.005 \mathrm{D}_{\mathrm{T}, \mathrm{m}}$ in the axial direction.

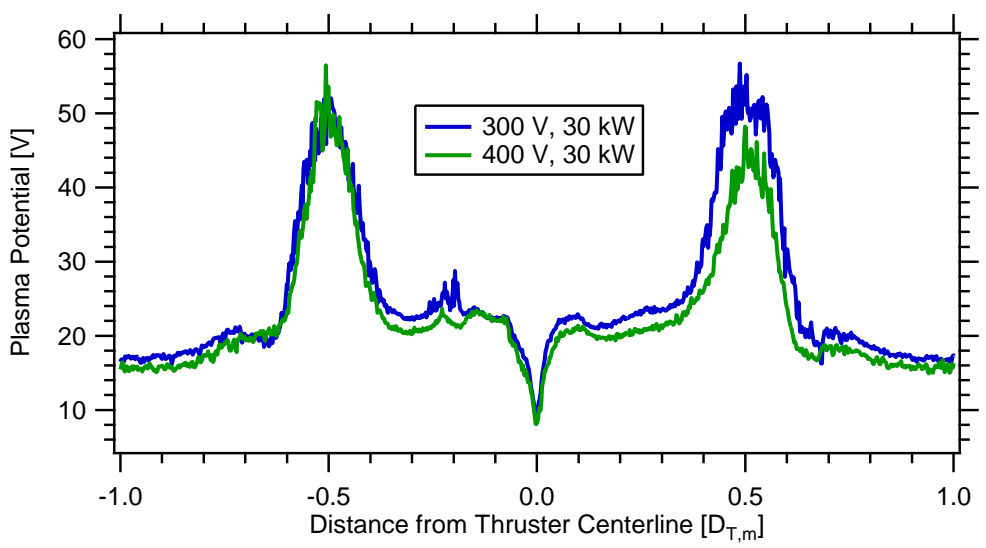

Figure 18. Radial profiles of measured plasma potential at $0.08 \mathrm{D}_{\mathrm{T}, \mathrm{m}}$ from the thruster exit plane, at 300 and $400 \mathrm{~V}, 30$ kW. While the two interrogated sides of the thruster are very similar, they are not perfectly symmetric. 


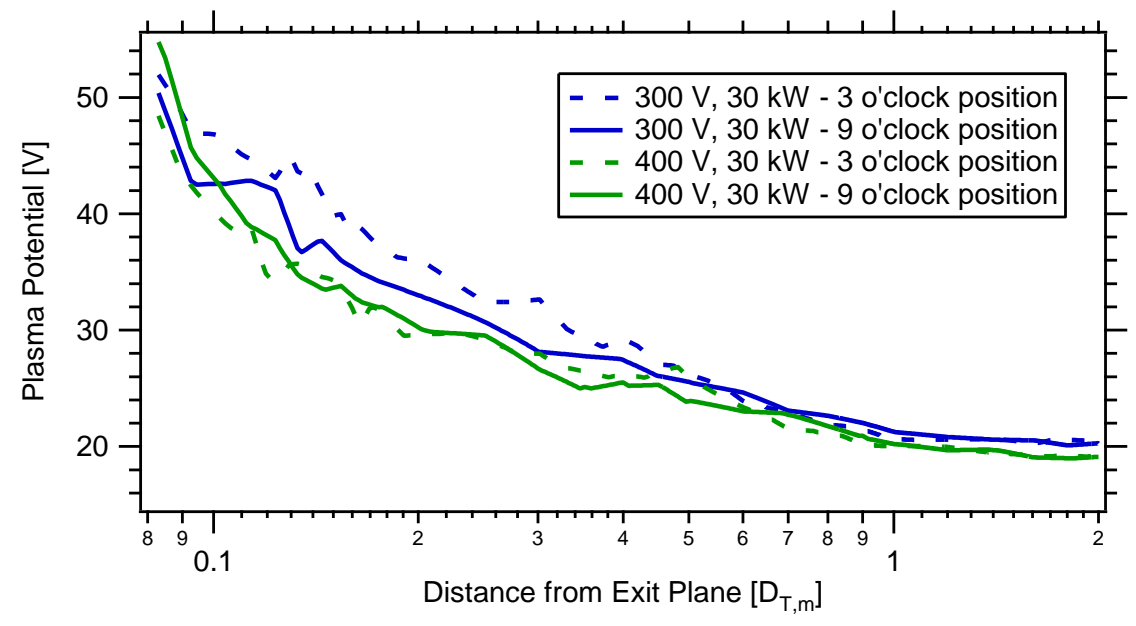

Figure 19. Axial profiles of measured plasma potential along both interrogated channel centerlines, at 300 and $400 \mathrm{~V}$ and $30 \mathrm{~kW}$. Even when plotted on a logarithmic distance scale, the two sides of the thruster match fairly well.

\section{Conclusions}

In order to aid the design of future high-power Hall thrusters and provide experimental data for validation of ongoing modeling efforts, an electrostatic probe array was used to interrogate the near-field plume of the NASA$457 \mathrm{Mv} 2$ Hall thruster. The acceleration zone at 300 and $400 \mathrm{~V}$ was found to be limited to within $0.4 \mathrm{D}_{\mathrm{T}, \mathrm{m}}$ of the thruster exit plane, while the high-temperature region was found to be within $0.25 \mathrm{D}_{\mathrm{T}, \mathrm{m}}$ of the exit plane at all four operating conditions presented. Measured electron temperatures in this region indicate that isothermal lines exhibit a similar shape to the magnetic field topology. Such a structure tends to create a high-temperature region in the vicinity of the magnetic poles, which causes the floating potential to drop to as low as $-90 \mathrm{~V}$ with respect to ground. Data within the acceleration zone indicates a higher degree of electron heating than prior measurements on other thrusters. However, more data is required to fully understand the relationship between the electron temperature and plasma potential in the NASA-457Mv2. Comparison between the two sides of the thruster indicates a relatively high degree of axisymmetry. The data taken in this study are considered valuable for the future design of highpower Hall thrusters as well as validation of Hall thruster models.

\section{Acknowledgments}

The authors would like to thank and acknowledge the Office of the Chief Technologist for funding this work as well as Timothy Smith for serving as the Project Manager. The authors would also like to thank Thomas Haag and Kevin McCormick for their aid in designing and building the probe mount used in this study, George Readus for installing the probe motion system used, as well as George Jacynycz and Kevin Blake for maintaining and operating the vacuum facility.

\section{References}

${ }^{1}$ Jacobson, D. T., Manzella, D. H., Hofer, R. R., and Peterson, P. Y., "NASA's 2004 Hall Thruster Program," Presented at the 40th AIAA/ASME/SAE/ASEE Joint Propulsion Conference and Exhibit, AIAA-2004-3600, Fort Lauderdale, Florida, July 1114, 2004.

${ }^{2}$ Manzella, D., Jankovsky, R., and Hofer, R. R., "Laboratory Model $50 \mathrm{~kW}$ Hall Thruster," Presented at the 38th AIAA/ASME/SAE/ASEE Joint Propulsion Conference and Exhibit, AIAA-2002-3676, Indianapolis, IN, July 7-10, 2002.

${ }^{3}$ Peterson, P. Y., Jacobson, D. T., Manzella, D. H., and John, J. W., "The Performance and Wear Characterization of a HighPower High-Isp NASA Hall Thruster," Presented at the 41st AIAA/ASME/SAE/ASEE Joint Propulsion Conference and Exhibit, AIAA-2005-4243, Tucson, AZ, July 10 - 13, 2005.

${ }^{4}$ Herman, D. A., Shastry, R., Huang, W., Soulas, G. C., and Kamhawi, H., "Plasma Potential and Langmuir Probe Measurements in the Near-field Plume of the NASA 300M Hall Thruster," Presented at the 48th AIAA/ASME/SAE/ASEE Joint Propulsion Conference and Exhibit, Atlanta, GA, July 29 - August 1, 2012. 
${ }^{5}$ Huang, W., Shastry, R., Herman, D. A., Soulas, G. C., and Kamhawi, H., "Ion Current Density Study of the NASA-300M and NASA-457M v2 Hall Thrusters," Presented at the 48th AIAA/ASME/SAE/ASEE Joint Propulsion Conference and Exhibit, Atlanta, GA, July 29 - August 1, 2012.

${ }^{6}$ Kamhawi, H., Haag, T. W., Jacobson, D. T., and Manzella, D. H., "Performance Evaluation of the NASA-300M 20 kW Hall Effect Thruster," Presented at the 47th AIAA/ASME/SAE/ASEE Joint Propulsion Conference and Exhibit, AIAA-2011-5521, San Diego, CA, July 31 - August 3, 2011.

${ }^{7}$ Soulas, G. C., Haag, T. W., Herman, D. A., Huang, W., Kamhawi, H. et al., "Performance Test Results of the NASA-457M v2 Hall Thruster," Presented at the 48th AIAA/ASME/SAE/ASEE Joint Propulsion Conference and Exhibit, Atlanta, GA, July 29 - August 1, 2012.

${ }^{8}$ Mikellides, I. G., Katz, I., Hofer, R. R., Goebel, D. M., De Grys, K. et al., "Magnetic Shielding of the Acceleration Channel Walls in a Long-Life Hall Thruster," Presented at the 46th AIAA/ASME/SAE/ASEE Joint Propulsion Conference and Exhibit, AIAA-2010-6942, Nashville, TN, July 25 - 28, 2010.

${ }^{9}$ Mikellides, I. G., Katz, I., Kamhawi, H., and Vannoord, J. L., "Numerical Simulations of a 20-kW Class Hall Thruster Using the Magnetic-Field-Aligned-Mesh Code Hall2De," Presented at the 32nd International Electric Propulsion Conference, IEPC2011-244, Wiesbaden, Germany, September 11-15, 2011.

${ }^{10}$ Jameson, K. K., "Investigation of Hollow Cathode Effects on Total Thruster Efficiency in a 6 kW Hall Thruster," Ph.D. Dissertation, Aerospace Engineering, University of California Los Angeles, 2008.

${ }^{11}$ Jameson, K. K., Goebel, D. M., Hofer, R. R., and Watkins, R. M., "Cathode Couplings in Hall Thrusters," Presented at the 30th International Electric Propulsion Conference, IEPC-2007-278, Florence, Italy, September 17-20, 2007.

${ }^{12}$ Lobbia, R. B. and Gallimore, A. D., "High-speed dual Langmuir probe," Review of Scientific Instruments 81, 7, 073503-1 073503-9 (2010).

${ }^{13}$ Hershkowitz, N., in Plasma Diagnostics: Discharge Parameters and Chemistry, edited by Flamm, D. L. (Academic Press, Inc., 1989), pp. 113-181.

${ }^{14}$ Lieberman, M. A. and Lichtenberg, A. J., Principles of Plasma Discharges and Materials Processing, Second ed. (John Wiley \& Sons, Inc., Hoboken, NJ, 2005).

${ }^{15}$ Haas, J. M., "Low-Perturbation Interrogation of the Internal and Near-Field Plasma Structure of a Hall Thruster Using a High-Speed Probe Positioning System," Ph.D. Dissertation, Aerospace Engineering, University of Michigan, 2001.

${ }^{16}$ Linnell, J. A., "An Evaluation of Krypton Propellant in Hall Thrusters," Ph.D. Dissertation, Aerospace Engineering, University of Michigan, 2007.

${ }^{17}$ Reid, B. M., "The Influence of Neutral Flow Rate in the Operation of Hall Thrusters," Ph.D. Dissertation, Aerospace Engineering, University of Michigan, 2008.

${ }^{18}$ Hofer, R. R., "Development and Characterization of High-Efficiency, High-Specific Impulse Xenon Hall Thrusters," Ph.D. Dissertation, Aerospace Engineering, The University of Michigan, 2004.

${ }^{19}$ Raitses, Y., Staack, D., Smirnov, A., and Fisch, N. J., "Space charge saturated sheath regime and electron temperature saturation in Hall thrusters," Physics of Plasmas 12, 7, 073507-1 - 073507-10 (2005). 